\title{
DISCOVERING AND SHARING OF SECRET ARCHITECTURES: THE HIDDEN TOMB OF THE PHARAOH OF EL-KHASNEH, JORDAN
}

\author{
Eva Savina Malinverni ${ }^{\mathrm{a}}{ }^{*}$ Roberto Pierdicca ${ }^{\mathrm{a}}$ \\ ${ }^{a}$ Universtitá Politecnica delle Marche, Dipartimento di Ingegneria Civile, Edile e dell’ Architettura \\ Via Brecce Bianche, 60100, Ancona, Italy (e.s.malinverni, r.pierdicca)@univpm.it
}

Commission II

KEY WORDS: Virtual Archaeology, 3D modeling, Visualization, Web Representation, Dense Points Cloud, Close Range Photogrammetry

\begin{abstract}
:
The documentation of the archaeological heritage through 3D models to know ancient findings, has become a common practice within the international panorama. Using minimal hardware, as well as its ease of use in almost every environmental condition, make 3D sampling solutions based on Multiple View Stereo (MVS) matching and Structure from Motion techniques ideal for on-site documentation of excavations or emergencies. Moreover, the availability of inexpensive platforms for web-based visualization represents great benefit in the field of archaeology, where generally the low budged and the limitation of more complex instruments are a must. The case study presented in these pages, experienced in Petra, Jordan, moves towards this direction. In the close proximity of the El- Khasneh façade, is situated an excavation where two entrance, well preserved, give access to the Tomb of Pharaoh. The documentation described in these pages has the twofold objective of providing the research community with a priceless dataset, acquired for one of the most important heritage of the world that is partially still unknown and to share on line these computations. This work confirms how cultural heritage documentation and dissemination of architectural rests, that are important for tourism and their interactive visualization, can strongly benefit from the creation of 3D models and their sharing on the web. This particular archaeological setting is an interesting base for investigation, given the complexity of the structure and its precarious condition.
\end{abstract}

\section{INTRODUCTION}

Given the large adoption of digital photogrammetry for the virtual reconstruction of ancient artifatcs, the use of 3D models to represent archaeological findings has become a common practice within the international panorama. The use of minimal hardware, (essentially, just a digital camera is enough to collect an useful dataset for documentation aims), and the ease of use in almost every environmental condition, make 3D sampling solutions based on Multiple View Stereo (MVS) (Seitz et al., 2006) matching and Structure from Motion techniques ideal for on-site documentation of archaeological excavations or emergencies (Pierdicca et al., 2016), (Manferdini et al., 2016). Moreover, the availability of inexpensive platforms for web-based visualization represents great benefit in the field of archaeology, where generally the low budged and the limitation of more complex instruments are an usual condition. Whilst some masterpieces are well documented and spread also among the non-expert users, it is worthwhile to mention the importance of less visible findings, that remain conceived to the vast majority of the visitors (Pierdicca et al., 2015). Often, awkward visit path or risks for the visitors oblige the heritage authorities to hide (also for preservation reasons), important findings that should be promoted and diffused among the presentday users. This is a common issue in nowadays archaeological settings, where the high costs of maintenance and management, as well as the need for preservation, persuade the heritage managing authorities to conceive some parts of the site, preventing them to be uncovered by the visitors (Bosco et al., 2015).

The case study presented in these pages, experienced in Petra, Jordan, moves towards this direction. In the close proximity of

\footnotetext{
${ }^{*}$ Corresponding author
}

the El-Khasneh façade, is situated an excavation where two entrances, well preserved, give access to the Tomb of Pharaoh. Petra is the most important archaeological site of Jordan, recognized as World Humanity Heritage by the UNESCO in the 1985, as well as one of the seven wonder of the world. The monument shows many façades carved into the rock, which make it a unique monument. The Pharaoh's Treasure is one of the most famous monuments of the whole archaeological site. Even if the Treasure of the Pharaoh is the most known monument (see Figure1 a), just a decade ago were discovered, at its base, some entrances to the tombs, probably attributable to the family of Areta IV. This entrance today is unreachable to the public, since it is covered by a dense iron grid and inaccessible to the visitors (see Figure $1 \mathrm{~b}$ ).

During a survey campaign organized by CNR ITABC and University of Molise to apply different techniques for the study of the area and the monuments (laser scanner and geophysical instruments) the authors were invited to perform the topographic support. In this occasion it happened to acquire by low cost close range photogrammetry the hidden archaeological findings below the El-Khasneh tomb. Since the tomb is hidden and difficult to reach, a set of images where acquired, performing a fast and unplanned survey and having the possibility to document a priceless monument, that is still unknown to the majority of the practitioners and researchers. A dataset of photographs allowed to perform a complete virtual reconstruction of these entrances; hence, the $3 \mathrm{D}$ models have been then optimized for the visualization on a web-based platform to allow data access to a wider range of users, spreading the knowledge of these entrances, that is unknown and unreachable to the public.

The work of virtual reconstruction and the following phase of virtualization for the web sharing was conducted taking into consid- 


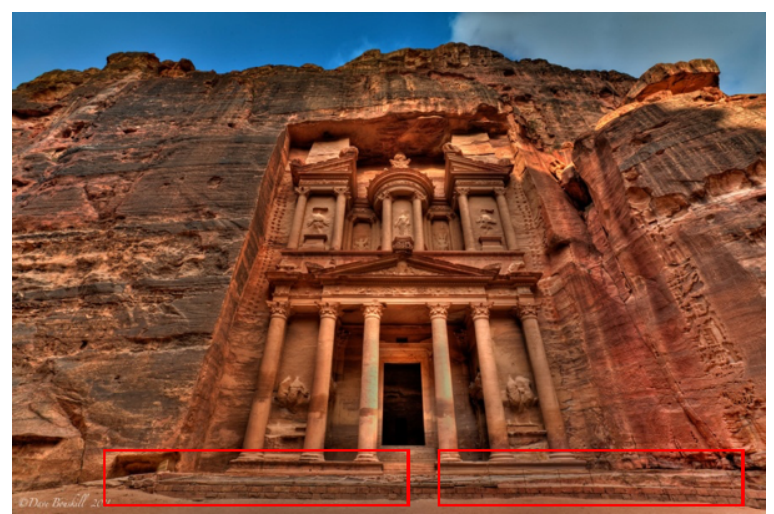

(a)

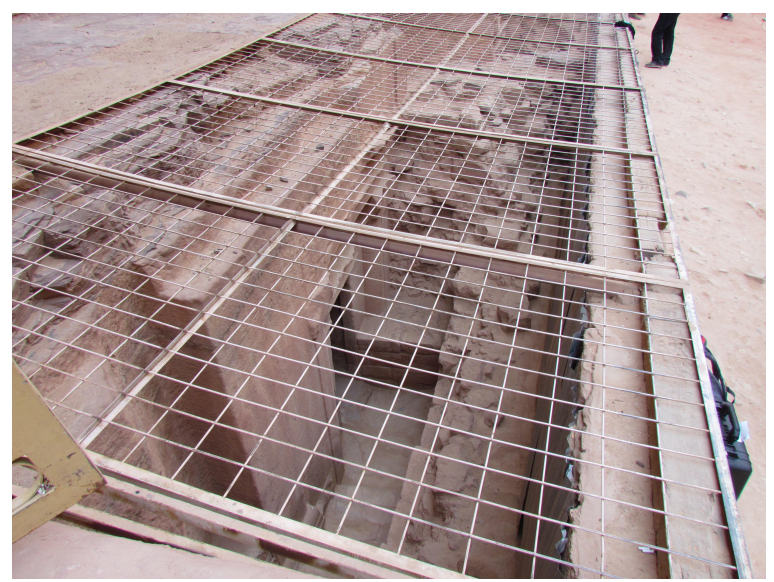

(b)

Figure 1. The Treasure of the Pharaoh. (a): El-Khasneh façade with highlighted at its bottom the iron grid covering the conveived doors. (b): the entrance doors of the excavation area, under the main building.

eration the rules outlined by the archaeological charts, mentioned in the Subsection 3.3.1, to show how such guidelines should be followed as the backbone for the dissemination of our priceless heritage.

This work confirms how cultural heritage $(\mathrm{CH})$ documentation and dissemination of architectural rests, that are important for tourism and their interactive visualization, can strongly benefit from the creation and diffusion of 3D models. In fact, so far, $\mathrm{CH}$ applications deal with the visualization by using desktopbased multimedia solutions and museums installations. The use of web solution should become the paramount media for disseminating $\mathrm{CH}$ knowledge. Exploiting the use of 3D digital technologies, is possible to provide scholars with new perspective to improve the quality of representations, useful to explain the results of their investigations. The reasons of these improvements are twofold: the use of fast and agile procedures of data acquisition provides practitioners with an immediate solution for unplanned surveys; moreover, the digital outputs can therefore be exploited through different media in different contexts, ranging from multi-resolution documentations to virtual reconstructions. Thus, the potential of virtual reconstruction lies in the possibility to positively influence the understanding of the reality, regardless from the purpose that drove a given data collection. The manipulation of spatial information and their simulations is essential in those contexts where artifacts are still uncovered or unreachable due to the reasons mentioned above. This aspect has sensi-

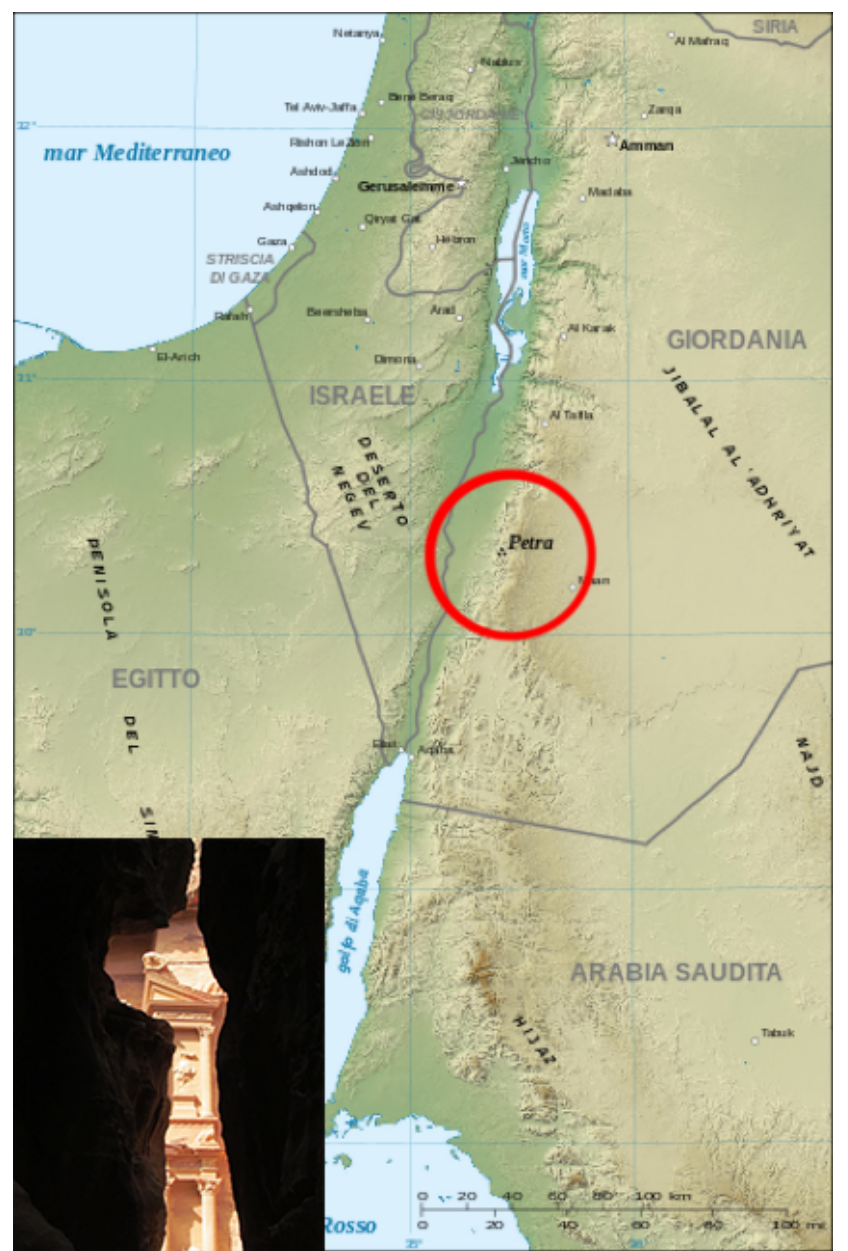

Figure 2. The geographical localization of the archaeological site with a frame of the throat leading to Khasneh.

bly improved the possibilities to exchange information between different disciplines, with evident benefits in knowledge sharing and in scientific research. 3D digital representation can therefore be considered as a powerful knowledge tool, as well as effective communication instruments. The actual conditions of the El-Khasneh site, object of this research, are noteworthy. In fact, the buildings are made of clay, a perishable material that can be badly affected by weather agents or humans activities. The documentation described in these pages has the twofold objective of providing the research community with a priceless dataset, acquired for one of the most important heritage of the world that is partially still unknown and to share on-line these elaborations. This particular archaeological setting is an interesting base for investigation, given the complexity of the structure and its precarious condition.

\section{HISTORICAL AND ARCHAEOLOGICAL CONTENTS}

Petra (Jordan) is situated half way between the Gulf of Aqaba and the Dead Sea, at a height between 800 and 1396 meters above sea level (the urban area is located around $900 \mathrm{~m}$ ) in the mountainous region of Edom to the east of Wadi Araba (see Figure 2).

Petra is a unique archaeological site in its gender, declared in 2007 one of the seven wonder of the world. From 1985 is under the safeguard of UNESCO, elected in the List of World Heritage. 


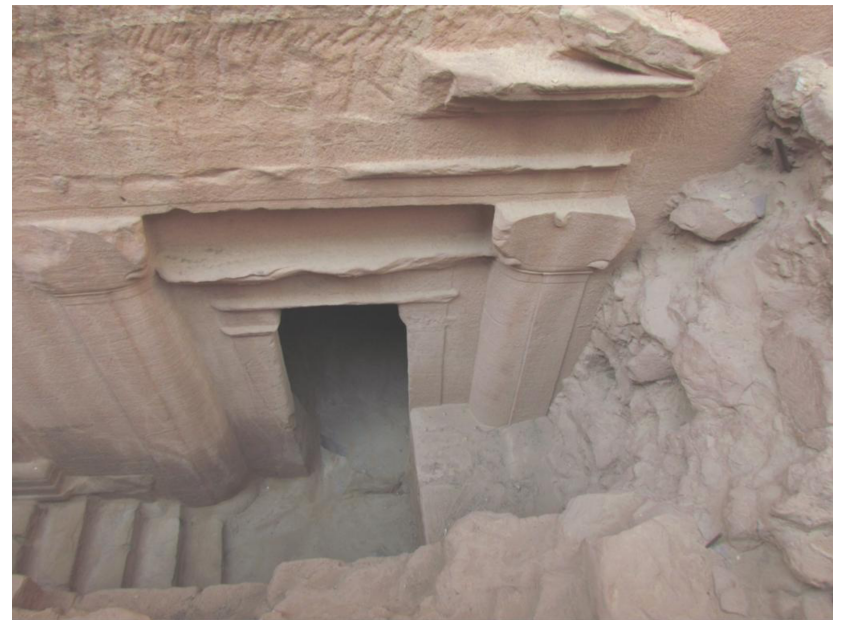

Figure 3. One of the doors, the right one, that are object of the $3 \mathrm{D}$ reconstruction.

The site, also known as the "Pink City", is characterised by countless façades that are unique because of their material and color; it was the place of several civilization and has witnessed, among the years, to a succeeded of periods which moulded the shape of its architectures: Edomites, Roman, Byzantine and Nabataean. To this last, experts ascribe the architectural style, with the main peculiarity of appearing to be graven directly on the stone. The techniques used to built up these magnificent monuments were basically two: the first one consisting on the extraction of blocks of stones directly from the side of the mountain. For achieving this result, Nabataean population used to create holes into the stone, within which they put wooden slab that, once filled of water, increased their volume cracking with perfect geometry the stone. The second was based on sculpting the stones directly from the mountain, proceeding from the top to the bottom in away to not damage the already done work. One of the most important task that these buildings had to fulfil was to store huge amount of water; for this reason, archaeologists consider the site as an example of hydraulic engineering. In fact, it is because of this masterly system that the life was possible in such a dry area (Bourbong, 2010). However, the most fascinating building in Petra is without any doubt the monumental façade of El Khasneh, a rocky monument built between 100 b.C. and 200 a.C.; the experts are in doubts about the origin of El Khasneh and they still didn't date back to it's nature or function. The majority of them agreed on assigning a sepulchral value to the building, mainly due to the fact that most of the masterpieces in Petra are tombs. Giving value to this hypothesis, on the proximity of the entrance, are placed two doors underground with respect to the level of the main entrance, discovered during a recent excavation (see Figure 3).

These doors (unreachable for the public and conceived below two iron grid) are in different state of conservation: the one on the left is undamaged, whist the one on the right present noticeable signs of abandon, especially on the head pediment. The access to these entrances is not allowed to the visitors, but once upon a time was possible thanks to a set of stairs that bring towards a wide room, used as temple and devoted to a god or to a deceased king. Thanks to the intuition of a Jordan archaeologist, the doors where discovered in 2003, since a subsidence of the sand surrounding the building was suggesting the presence of rooms placed underground. During the excavation phase, several skeletons were discovered, thanks to whom was possible to understand the origin of the building, indeed a tomb. The two entrance doors just described represent the object of this work, with the methodology described in the following section.

\section{METHODOLOGY}

The extreme importance of preserving (or at least documenting) this kind of heritage underpins several factors, that can be summarized in the following issues: commonly, the sites are extremely wide, making difficult to perform a complete visit for a tourist; moreover, many artefacts or buildings are unreachable and invisible because of protection reasons. In this scenario, the use of new media of communication would become essential to spread to the mankind those unknown architectures. Some technologies, like Augmented Reality for instance, allows the visualization of artifacts that are not visible because they are conceived due to conservation issues, or because they are no more existing. However, the use of such solutions requires the user to be directly on the site to visualize models like they appear underground or like they appeared in ancient years (Pierdicca et al., 2015). Also Virtual Reality (VR) can be a suitable approach (Herrmann and Pastorelli, 2014), but to experience VR in the proper way is mandatory to adopt bulky and often expensive hardware, that could generally be exploited on a museum scenario. Hence, the remote visualization on the WEB of complex geometry might probably represent the more suitable solution. This is also because, in the last few years, the WebGL framework allowed to overcome the proprietary plugins issue, and three-dimensional content is slowly becoming a usual type of content for web pages (Potenziani et al., 2015). The core component of this approach, is, obviously, the 3D model. Nowadays, thanks to the introduction of several algorithm of dense matching (Doneus et al., 2011), it is allowed to achieve a photo-realistic modelling, just handling a camera to perform an image acquisition. This represent a huge advantage, since there are places and sites around the world where it is hard to carry heavy, large or even expensive equipment. However, digital cameras are extremely portable and easy to use (Cabrelles et al., 2010). In fact, it is well known that excavations are generally conducted in emergency conditions, surveys are often unprogrammed and the documentation of findings is a hard task during the campaigns. The work-flow presented for this case study has the purpose to outline best-practices in the field of archaeology, from the survey phase until the dissemination and fruition through the sharing on web platforms. The introduction of new photogrammetric techniques acquisition and cutting edge solution for the visualization of rests are mandatory for both conservation/documentation and promotion of archaeology. With our approach we provide:

- Free and low cost solutions allowing unplanned data acquisition;

- Rapid and smart techniques to facilitate documentation during excavation work;

- High level of detail for the representation of complex 3D objects;

- Contextualized visualization of archaeological findings.

The procedure of the creation of the model, that is well established in the literature (Doneus et al., 2011), consists of data acquisition (imagery and ground control point), self-calibration bundle adjustment of the dataset, $3 \mathrm{D}$ transformation, dense image 


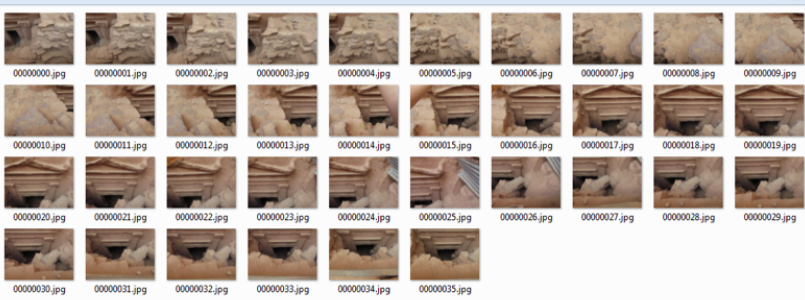

Figure 4. The set of images shot during the acquisition campaign: in this example, the images of the left door are reported.

matching, meshing and texturing; in the following, these steps are described. To achieve a final model of the entrance doors, a state of art workflow have been performed; after the orientation of the dataset, the sparse dense cloud was produced. The dense matching phase created the dense cloud, from which we created the meshes and textures suitable to complete the virtual reconstruction of the monument. Afterwards, a tidy process of cleaning, simplification and optimization of the model allowed to get a final model, suitable to be managed on a web platform.

\subsection{Survey}

During the campaign in Petra, to perform the 3D survey others researchers of the team used different types of technologies such as GPS, laser scanner or spherical photogrammetry to perform the surveying of the tomb, inside, outside and the surrounding (D'Annibale, 2011). However, these techniques require an accurate a priori planning of the survey campaign, as well as a costly and cumbersome equipment. Only in this area, underground the façade, we faced with a condition of unprogrammed survey and not achievable artifact, so that just a set of images could be used for the 3D reconstruction. For photogrammetric recordings, a Power Shot sx30is digital camera was used, which provides a maximum resolution of about 14.1 MPx. A total of 36 images for the left door and 46 images for the right one were taken. The images were acquired keeping the camera at the focal length of $40 \mathrm{~mm}$, with the highest resolution (4320 x 2340 pixels), with an overlap of about $30 \%$ (one of the set of pictures is reported in Figure 4) All the well-known rules were respected for the acquisition; for instance, the focal length was kept constant and pictures were taken from the top of the iron grid in a pseudo-nadiral configuration, in order to have a full coverage of the architecture; each picture from different Point of View (POV) has been used to proceed with the workflow that lead towards the creation for the 3D model. In both cases, the configuration of acquisition was pseudo nadiral for the pave and oblique for the pediments. From the dense cloud it is possible to get the 3D model of both parts of the excavation.

\subsection{Data processing}

For the 3D model reconstruction of the findings we adopted Structure from Motion (SfM) techniques (Furukawa and Ponce, 2009). For our work we used both Photosynth coupled with PMVS-2, both open source software able to create 3D content from still images (Pomaska, 2009). The software Photosynth is able to compute the relative position of the photographs and the direction of the shots (see Figure 5). This stage of the process can produce just the sparse point cloud, arising from the orientation phase achieved with the identification of the tie points between the images.

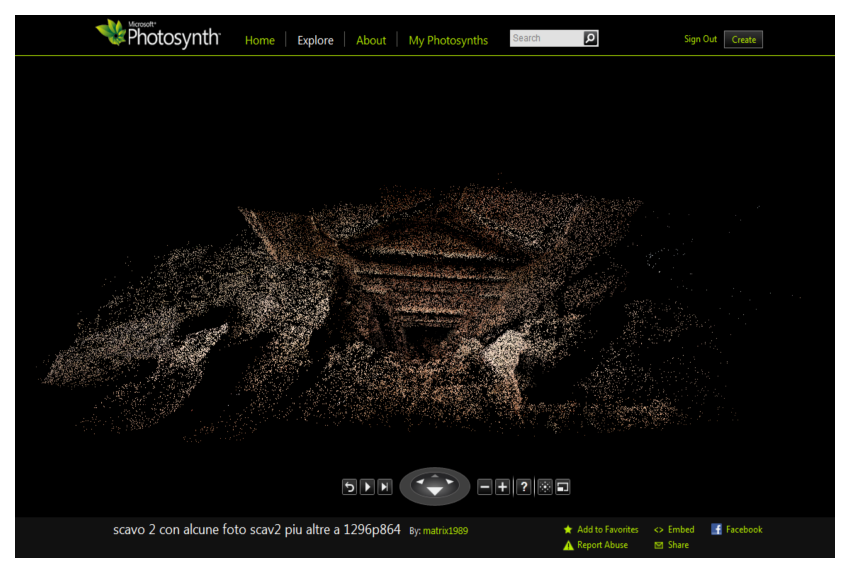

Figure 5. The sparse cloud after the orientation phase computed with Photosynth. The point clouds are suitable for a preview of the excavation directly on the web platform.

Hence, starting from the set of images uploaded on the web service provided by Microsoft and once obtained the orientation parameters, PMVS-2 suite is able to built the dense point cloud. The output is a .ply file which bring the points coordinates and the information about the texture, as reported in Figure 6

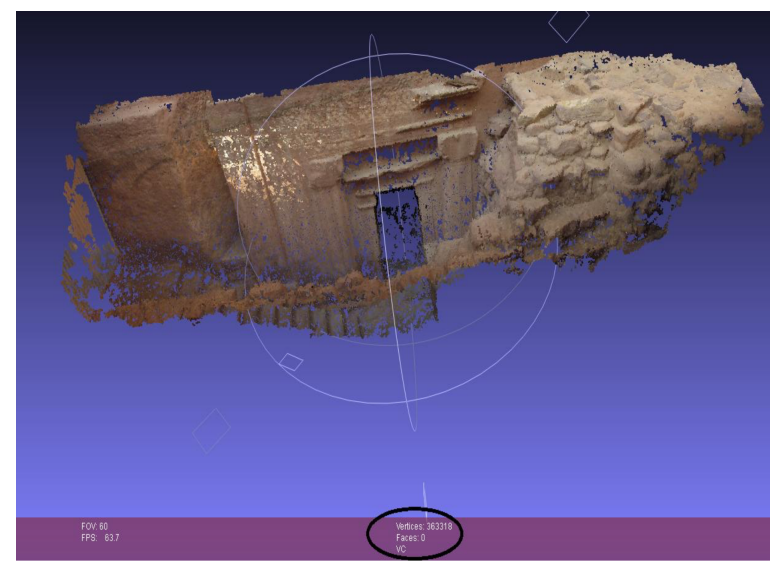

(a)

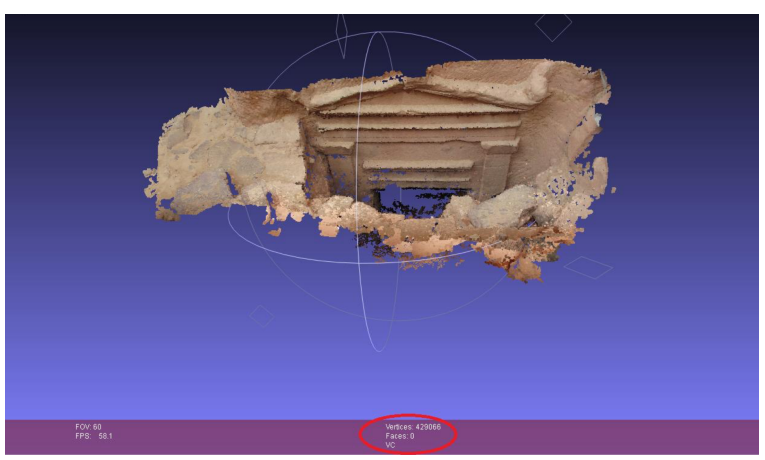

(b)

Figure 6. The dense point clouds of the excavation after the computation with PMVS-2. (a) and (b) represent respectively the door on the left and the door on the right.

Several tests have been conducted in order to achieve the right balance between the number of points and the resolution of the textures. 


\subsection{Creation of the Model}

MeshLab (an open source system developed at the visual computing lab of ISTI- CNR) have been employed to create the meshes of the doors, filtering data and other post-processing tasks like cleaning and filling of the holes. Holes were manually closed with a manual identification process, choosing the best closing algorithm for every single hole included into the software. In Figure 7 some images of the 3D model obtained are reported.

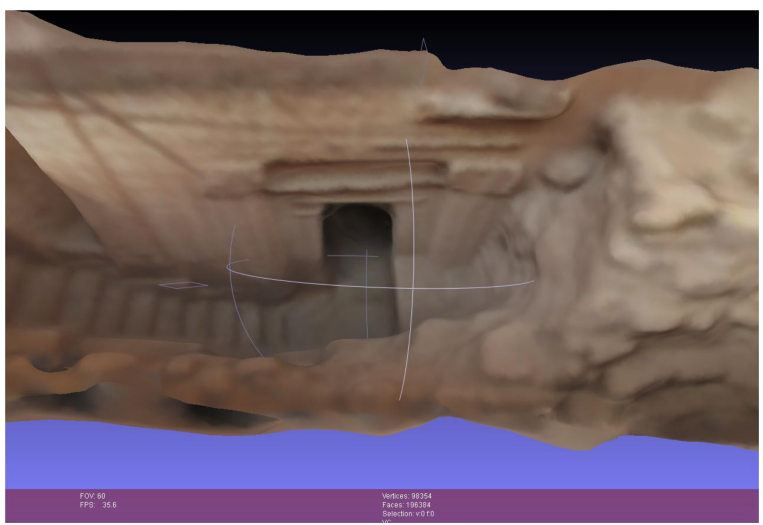

(a)

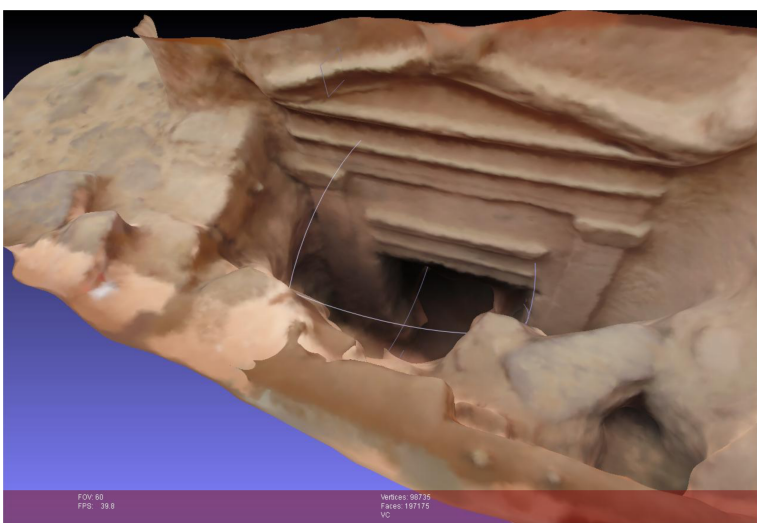

(b)

Figure 7. The 3D models of the doors, obtained after the computation with MeshLab. (a) and (b) represent respectively the left and right doors of the underground area of the El-Khasneh

During the image acquisition of the excavation, the existence of the iron grid and ground covering the doors, prevented a complete and whole surveying. For this reason, the two doors have been treated like separated elements. However, in order to produce a single element to be shared on line as a whole, a further step of conjunction of the two surveys was performed. To achieve this result, we identified some tie points between the two point clouds. Thus, by aligning the two chunks, we obtained the result showed in Figure 8.

The model was scaled according to the real measures taken manually (using the iron grid as a reference system), and geo-referenced using these measured Ground Control Points (GCPs). Through this step, the 3D model is rotated and scaled in order to fit into the relative coordinate frame. To perform this task, it was sufficient to import the coordinates (in .txt format) of a dozen of GCPs and indicating their position on the photographs by manually picking the corresponding point directly in MeshLab. Due to the lack of tie point in common with the topographic survey, a geo-referencing in an absolute coordinate frame was not possible.

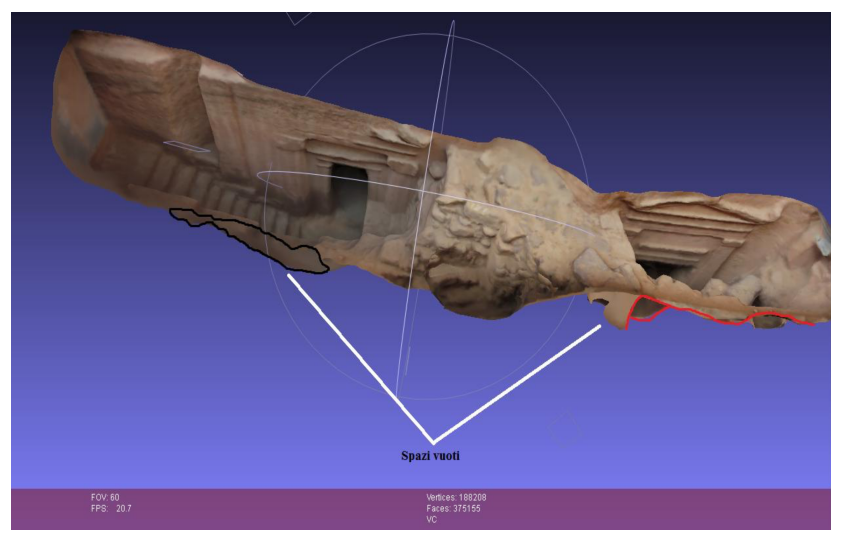

Figure 8. The final result of the reconstruction workflow ends up with the combination of the two doors into one single 3D model. In the figure is clear the perfect alignment between the two models.

At this stage, after a tidy process of simplification and optimization, the 3D model is ready to be shared on the web. Before to describe this last step, is due to mention in a brief focus about the virtualization of the archaeological heritage, nowadays ruled by several charts that in the following.

3.3.1 Virtualization in Archaeology Virtual archaeology is a domain of archaeology that emerged in the last decade, also thanks to the growing number of web platforms and sites devoted to the discovering of far and ancient sites. V-Must ${ }^{1}$ and Zamani ${ }^{2}$ project are just some examples that is worthwhile to cite. The potential of three-dimensional representation applied to archaeology is growing its interest in research and applications. One of the most viable alternatives used involves 3DHOP's software (3D Heritage Online Presenter) which is an open-source software package used for the creation of interactive web presentations of high-resolution 3D models, oriented to the $\mathrm{CH}$ field. 3DHOP target audience ranges from museum curators, with some ICT experience, to the experienced web designers, who want to embed 3D contents in their creations; also students in the $\mathrm{CH}$ field or small companies developing web applications for museum and $\mathrm{CH}$ institutions can benefit from the tool ((Potenziani et al., 2015)). Regardless from the platform, or method, is used to share the results of a survey, it is mandatory to undergo some rules and best practices, recognized at international level, that have been outlined by the experts in the field of virtual archaeology. In the following, these rules have been briefly summarize, in a sort of state of art of the available charters.

3.3.2 Best practices for virtual archaeology: the last charters The charts are addressed towards two kinds of end users, mainly with two specific purposes:

- scientific purposes, mainly addressed to the technicians, who are in charge of representing in the proper way all the specifics which feature the buildings (illumination, volumetric ratio, public and private spaces and so on)

- dissemination purposes, mainly addressed to the wide public, since as said before the new communication media have the main aim of allowing the exploration of ancient sites also from afar, (for instance through virtual tours) discovering and sharing their knowledge.

\footnotetext{
${ }^{1}$ http://www.v-must.net

${ }^{2}$ http://zamaniproject.org
} 
2000: The Cracow Charter - Principle for the conservation and the restoration of Cultural Heritage This chart was written as an extension of a previous chart of 1964 (the Chart of Venice), that was an international guideline for the conservation and restoration operations, for archaeological and historical buildings. For the first time the Cracow Chart included the use of digital technologies in this field. The specification was the following: "For the safeguard and the dissemination to the public of the $\mathrm{CH}$, the use of modern technologies like data base, information systems and virtual representations should be promoted". This specification represents an important turning point in the use of new media for the heritage goods preservation and dissemination, so that this chart be considered the first milestone of the virtual archaeology paradigm, since it pioneered its meaning.

\section{6: London Charter for the Use of 3D Visualisation in the} Research Communication of Cultural Heritage With the growing use of 3D virtual reconstructions of the last decade, in 2006 was conceived the London Charter by a community of experts and archaeologists. The purpose of the document was to explicit with rigour the principle that one have to follow for the construction of computer-based experiences. Two main problems were highlighted:

- the lack of clearness of the reconstruction;

- the magnifying of the realism of the reconstruction.

The charter assumes that the principle are necessary in order to make the visualization of the goods intellectually and technically coherent with the other archaeological activities. All the ambit of computer vision have been kept into consideration (at a multidimensional level) trying to extend all these concepts also for museum replicas. Besides, a strong suggestion comes also not only with respect to the academia, but also to the entertainment industries dealing the $\mathrm{CH}$ dissemination. The following is the list of the aspect that one have to take into account for the digitization of ancient goods:

- Making available all the sources used to produce the reconstruction;

- Disclosing all the tools adopted;

- Disclosing all the hypothesis and assumption ;

- Proposing multiple hypothesis, especially for most complex cases;

- Proposing multiple hypothesis for each of the historical periods in which the artifact was build.

This charter has also the objective to assure accessibility and sustainability of the contents, in order to make them understandable, evaluated and visualized by the most of the people, but at the same time with scientific value. This charter represents a sort of backbone to pave the guideline for future implementations, identifying some principle that are briefly mentioned: the chart should be used every time scientists create a virtualization; the use of digital technology should be entrusted on the real usefulness of the method; the sources should be documented in order to maintain the integrity of the reconstruction; the content should be shared clearly and according to the purposes they have built for; a long term duration should be warranted to not lost the intellectual value within the digital material; it is important to evaluate a priori the impact that the use of digital technology might have on the knowledge of the good.

2008: ENAM Charter This Charter was approved by ICOMOS to dictate the guidelines for the interpretation and presentation of the $\mathrm{CH}$. One of the most important recommendation is the following: "Visual reconstructions, (from experts like artists, architects, 3D modeller) should be based on detailed analysis and on historical and archaeological resources like inscriptions, oral stories, iconography and photography. The virtual representation based on these information should be well documented and, if present, also the material for comparisons should be produced.

2011: The Seville Charter The Spanish Society of Virtual Archaeology (SEAV) settled the International Forum of Virtual Archaeology to establish the theoretical fundamentals for the future of virtual archaeology. The document is an enhancement with respect to the previously cited London Charter, since it easer the application criteria for experts, and also establishes the guidelines for a better comprehension of the archaeological activity in its whole. It points out the importance of visualization, highlighting how the promotion of archaeological findings with the new media should be responsible. It also should facilitate the management of the $\mathrm{CH}$. Finally, it also recommend to invest on the research and development of new applications and forms of interaction for the dissemination through digital tools.

\section{SHARING THE MODEL ON THE WEB}

As described in Section 3.3, the 3D model is ready to be used for different purposes; for archaeologists the maximum level of detail (LOD) is needful for documentation or restoration aims. However, such a high LOD requires very high computational expenses, and the 3D model would be unusable for touristic or public visualization purposes. This large amount of data makes the $3 \mathrm{D}$ objects very heavy; if the experience is designed for the web, their use could be affected. Hence, the correct balance between quality and size is mandatory, in order to assure a good user experience without compromising usability. In favour of this, the world of the web is positively changing, opening new frontiers for the visualization and interaction with complex 3D models. This change was possible thanks to the introduction of WebGL, a powerful and flexible graphics library derived from the world of OpenGL. WebGL offers the ability to render 3D scenes within any common browser. Through these tools it is possible to achieve the purpose of spreading complex information, by communicating the data collected in the field with digital photogrammetry techniques for a reality-based results. Archaeology is one of the fields that can benefit from the development of agile web 3D solutions, since the dissemination and fruition of cultural goods are strictly related to the use of digitizing tools and smart visualization systems (Tucci et al., 2011). Due to aforementioned portability issues, the model required a strong optimization. For the sharing on the web we decided to adopt an existing and open platform named SketchFab, based on open standards like html5 and WebGL libraries which allows to upload 3D models with an user friendly interface and to make them available to the community. The platform supports several format; in this case we adopted the .obj one. The platform also allows to manage several items related to the textures in order to show the contents in the proper way. The final web page achieved with the $3 \mathrm{D}$ model is reported in Figure 9. 


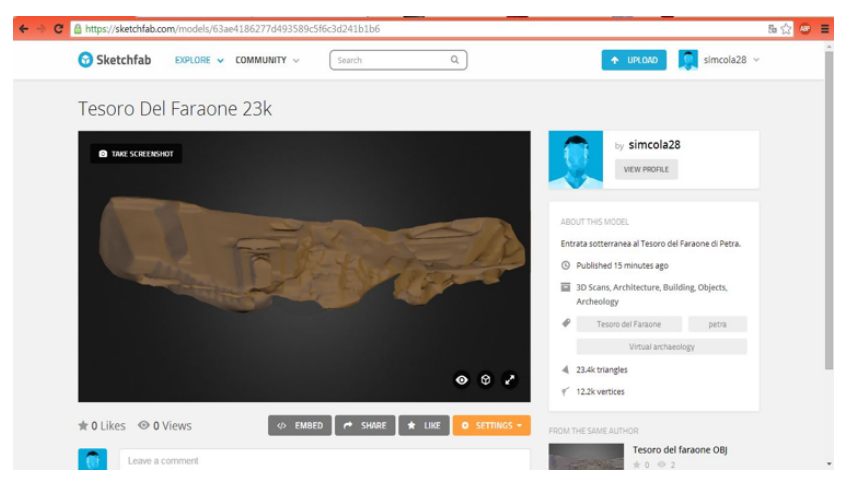

Figure 9. The visualization of the 3D model on the web browser, created with Sketch Fab.

\section{DISCUSSION AND CONCLUSION}

The future of worldwide $\mathrm{CH}$ is increasingly entrusted to its documentation with the new technologies. This means that researchers and practitioners have the responsibility to collect, compute and share their acquisitions with the wide public, in order to disseminate them and warranty to these priceless goods a second life. In the last decades we also witnessed to the growing of a new form of data collection directly from the tourists (Snavely et al., 2006) (namely crowd-sourced data ). But it seems not to be enough. Just think to the emergencies in the Syrian scenario, where countless goods disappeared because of the war and cannot be reconstructed since we have not enough digital material to proceed with their virtual reconstruction. The work described in this pages moves towards this direction. With the use of a simple camera and a suite of open source tools, we put at the disposal of the community a part of a famous monument that is unknown to the majority of the visitors. The limitation of the method is that, without any reference point in common with the rest of the building, it would be impossible to geo-localize properly the 3D model. Besides, without the possibility to evaluate the dimensions, it is not possible to put it within the real context. The reason of this lies in the lack of adequate planning of the survey, that led to an incomplete result. In the future, we plan to use the existing model of El-Kashne monument to contextualize the doors, using VR tools to see them in their real place. This would be useful since it is the only way to see these element, since in the reality their visit is not allowed.

\section{ACKNOWLEDGEMENTS}

The authors would like to thank the University of Molise and ITABC of CNR for involving the authors in the mission to Petra and the students Marchetti and Colasante for the data processing during their stage.

\section{REFERENCES}

Bosco, A., Barbarino, M., Valentini, R. and D'Andrea, A., 2015. Low-cost surveys of the domus of stallius eros in pompeii. ISPRS - International Archives of the Photogrammetry, Remote Sensing and Spatial Information Sciences XL-5/W4, pp. 187-192.

Bourbong, F., 2010. Petra: guida archeologica alla capitale Nabatea.

Cabrelles, M., Seguí, A., Navarro, S., Galcerá, S., Portalés, C. and Lerma, J., 2010. 3d photorealistic modelling of stone monuments by dense image matching. In: Commission V Sympo- sium, Newcastle upon Tyne, UK. International Archives of Photogrammetry, Remote Sensing and Spatial Information Sciences, Vol. 38number Part 5, pp. 121-124.

D'Annibale, E., 2011. Image based modeling from spherical photogrammetry and structure for motion. the case of the treasury, nabatean architecture in petra. Geoinformatics FCE CTU 6, pp. $62-73$.

Doneus, M., Verhoeven, G., Fera, M., Briese, C., Kucera, M. and Neubauer, W., 2011. From deposit to point cloud-a study of low-cost computer vision approaches for the straightforward documentation of archaeological excavations. Geoinformatics FCE CTU 6, pp. 81-88.

Furukawa, Y. and Ponce, J., 2009. Accurate camera calibration from multi-view stereo and bundle adjustment. International Journal of Computer Vision 84(3), pp. 257-268.

Herrmann, H. and Pastorelli, E., 2014. Virtual reality visualization for photogrammetric $3 \mathrm{~d}$ reconstructions of cultural heritage. In: International Conference on Augmented and Virtual Reality, Springer, pp. 283-295.

Manferdini, A. M., Gasperoni, S., Guidi, F. and Marchesi, M., 2016. Unveiling damnatio memoriae. the use of $3 d$ digital technologies for the virtual reconstruction of archaeological finds and artefacts. Virtual Archaeology Review 7(15), pp. 9-17.

Pierdicca, R., Frontoni, E., Malinverni, E. S., Colosi, F. and Orazi, R., 2016. Virtual reconstruction of archaeological heritage using a combination of photogrammetric techniques: Huaca arco iris, chan chan, peru. Digital Applications in Archaeology and Cultural Heritage 3(3), pp. 80-90.

Pierdicca, R., Frontoni, E., Zingaretti, P., Malinverni, E. S., Colosi, F. and Orazi, R., 2015. Making visible the invisible. augmented reality visualization for $3 \mathrm{~d}$ reconstructions of archaeological sites. In: International Conference on Augmented and Virtual Reality, Springer, pp. 25-37.

Pomaska, G., 2009. Utilization of photosynth point clouds for 3d object reconstruction. In: Proceedings of the 22nd CIPA symposium, Kyoto, Japan.

Potenziani, M., Callieri, M., Dellepiane, M., Corsini, M., Ponchio, F. and Scopigno, R., 2015. 3dhop a flexible platform for the publication and visualization of the $3 \mathrm{~d}$ digitalization results on web. ARCHEOMATICA-TECNOLOGIE PER I BENI CULTURALI 6(4), pp. 6-11.

Seitz, S. M., Curless, B., Diebel, J., Scharstein, D. and Szeliski, R., 2006. A comparison and evaluation of multi-view stereo reconstruction algorithms. In: Computer vision and pattern recognition, 2006 IEEE Computer Society Conference on, Vol. 1, IEEE, pp. 519-528.

Snavely, N., Seitz, S. M. and Szeliski, R., 2006. Photo tourism: exploring photo collections in $3 \mathrm{~d}$. In: ACM transactions on graphics (TOG), Vol. 25number 3, ACM, pp. 835-846.

Tucci, G., Cini, D. and Nobile, A., 2011. Effective 3d digitization of archaeological artifacts for interactive virtual museum. In: Proceedings of the 4th ISPRS International Workshop 3D-ARCH 2011. 